\title{
Magazine of
}

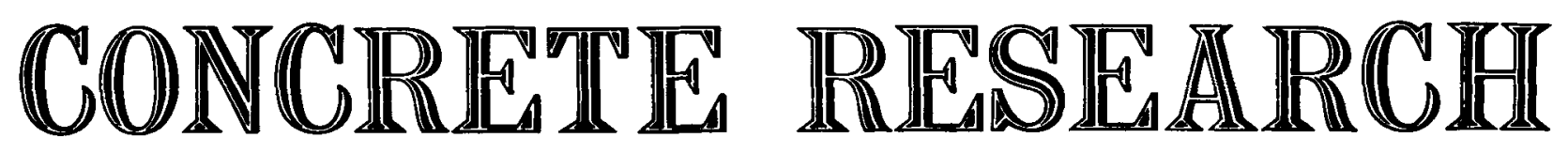

Volume 14, Number 40: March 1962

\section{EDITORIAL ADVISORY BOARD}

A. L. L. Baker, D.Sc.(Eng.), M.I.C.E., M.I.Struct.E.

Professor of Concrete Technology, University of London, Imperial College of Science and Technology

W. F. Cassie, Ph.D., M.S., F.R.S.E., M.I.C.E., M.I.Struct.E.

Professor of Civil Engineering, University of Durham, King's College, Newcastle upon Tyne

R. H. Evans, C.B.E., D.Sc., D.ès Sc., Ph.D., M.I.C.E., M.I.Mech.E., M.I.Struct.E.

Professor of Civil Engineering, University of Leeds

T. W. Parker, M.Sc., Ph.D., F.R.I.C.

Deputy Director of Building Research, Department of Scientific and Industrial Research

A. D. Ross, B.Sc., Ph.D., F.R.S.E., M.I.C.E.

Professor of Civil Engineering, University of London, King's College

SECRETARY TO THE BOARD AND EDITOR

Ralph P. Andrew, M.A., Ph.D.

Editorial Office : Wexham Springs, Framewood Road, Stoke Poges, Slough, Bucks : Fulmer 212 


\section{Editorial comment}

IN hIS LeCture to the Prestressed Concrete Development Group on 11 January 1962, Mr R. E. Rowe, in charge of research into structural design at the Cement and Concrete Association, gave a research engineer's view of the future of prestressed concrete.

Considering first the materials of prestressed concrete, $\mathrm{Mr}$ Rowe began by suggesting that cube strengths of 12,000 to $14,000 \mathrm{lb} / \mathrm{in}^{2}$ would become common. These could be achieved under closely controlled conditions, with appropriate methods of compaction (perhaps including the use of pressure) and curing. The permissible stresses associated with concrete of such strengths would certainly be about 4,000 to $6,000 \mathrm{lb} / \mathrm{in}^{2}$.

It was not, however, sufficient to consider the uniaxial compressive strength of concrete as the sole criterion, since in actual structures the concrete might be subjected to biaxial or triaxial stresses. It would seem logical to specify design stresses in the material appropriate to the stress field in which it was required to function. Recent research had shown that concrete in complex stress conditions could sustain between two and eight times the nominal cube strength without deterioration, and so the designer should be able to utilize design stresses greater than the cube strength where warranted.

With regard to tensile properties, the present restrictions imposed by codes of practice would have to be radically modified in the light of information obtained from research. Our present knowledge of the tensile stress-strain relation for concrete was very limited, particularly in regard to other principal stresses which might co-exist. Dr Abeles had for many years advocated the use of higher permissible tensile stresses in pre-tensioned concrete on the basis that the so-called micro-cracks that formed were in no way detrimental. Mr Rowe's own view was that it was not the stress but the strain that was of cardinal importance, because the tensile strain before cracking appeared to be a function of the degree of restraint in the tensile zone. The restraint might arise from composite action between in situ concrete and high-quality precast prestressed concrete, from well distributed wires in a pre-tensioned beam, or might be brought about by a complicated stress distribution. There is an apparent plasticity in tension that was of great importance in the stiffness of members: it might be possible to utilize higher permissible stresses in certain conditions.

Mr Rowe then considered concrete made with lightweight aggregates; strengths of $8,000 \mathrm{lb} / \mathrm{in}^{2}$ were already possible, and some higher figures might be expected in the future.

Of particular interest was the strength/density ratio. Rüsch ${ }^{(1)}$ had estimated that the limiting value for normal in situ concrete was likely to be $11 \times 10^{4}$ in. or $7,000 \mathrm{lb} / \mathrm{in}^{2}$ at a density of $0.065 \mathrm{lb} / \mathrm{in}^{3}\left(112 \mathrm{lb} / \mathrm{ft}^{3}\right)$. It seemed likely that, for a quality controlled product, a value of $14 \times 10^{4} \mathrm{in}$. might be reached or exceeded in the future for the strength/density ratio of both normal and lightweight concretes. The strength/density ratio of mild steel was $14 \times 10^{4}$ in., and so it seemed likely that concrete and steel could compete on the same basis as regards compression; as prestressing could, in general, take care of tensile stresses, prestressed concrete in the future could be regarded as having the same strength/density relation as mild steel in both compression and tension.

A recent development in cement research was the production of expansive cements ${ }^{(2,3)}$ with expansion properties considerably greater than before. When used in a $1: 2.75$ mortar, cured in water for 6 days and then in air for 120 days, these cements produced an expansion of $450-1,800 \times 10^{-6}$ (for clinker at $2,480^{\circ} \mathrm{F}$ ) or $5,000-10,000 \times 10^{-6}$ (for clinker at $2,550^{\circ} \mathrm{F}$ ).

Cement of this type had been used by Lin in the manufacture of a prestressed concrete slab $6 \mathrm{ft}$ square and 2 in. thick incorporating unstressed $\frac{1}{4}$ in. diameter high-tensile strands. The expansive action of the cement produced initial stresses of $121,000 \mathrm{lb} / \mathrm{in}^{2}$ in the strand which decreased to a residual stress of $95,000 \mathrm{lb} / \mathrm{in}^{2}$.

Such cement could have considerable scope in factory production of precast units, but much careful research would be required before the requisite degree of control could be achieved.

$\mathrm{Mr}$ Rowe concluded his survey of concrete as a material by emphasizing that our knowledge of the true failure criteria of concrete was still very limited. Future research would undoubtedly increase our knowledge, and lead to a revision of our ideas of permissible and ultimate load stresses. The information we already had suggested that this would mean higher values for these stresses.

Little development seemed likely in the high-tensile steel used for prestressing, apart from improvements in its stress relaxation properties by suitable treatment after drawing or rolling. The use of new alloy steels could not be ruled out, but there seemed little evidence of developments in this field applicable to prestressing.

The extremely high tensile strength of glass fibres had been known for many years, but it had only become possible to use this strength in rods with the introduction of polyester and epoxy resins. Rods of up to $\frac{1}{2}$ in. diameter containing up to $80 \%$ of glass fibre had been produced with tensile strengths similar to those of high-tensile steel but with a modulus of elasticity of between 5 and $7 \times 10^{6} \mathrm{lb} / \mathrm{in}^{2}$. By virtue of its low modulus, the material had the advantage of 
reducing the losses of prestress due to creep, shrinkage and elastic contraction to very low, if not negligible, values. Good bond had been achieved with rods up to $\frac{1}{4}$ in. in diameter. Resin-bonded glass fibre tape could be produced with superior bond and handling properties, and could be wound over bars of appropriate diameter at the ends of long-line beds, perhaps eliminating temporary anchorage costs.

The weakness of resin-bonded glass fibre at present was its relatively poor resistance to the effects of high temperature. This could be improved if better resins were developed. Until this was achieved, the use of the material would be limited to structures without fireresistance requirements, chiefly bridges.

Resins would become increasingly important as jointing materials, particularly when units were being post-tensioned together on site. Their use in the United Kingdom was, however, at present very much limited by their high cost.

$\mathrm{Mr}$ Rowe next mentioned some aspects of research into the properties of sections, to illustrate the benefits to design that would accrue from the application of information gained.

An increase in torsional strength with applied bending moment had been confirmed, associated in the case of $T$ beams with an increase in rotation in torsion. Such information was very important in the analysis of grillages and frameworks at ultimate load.

The problem of the design of end-blocks had been extensively studied, and it now seemed possible to produce an empirical design procedure for various shapes of end-block subjected to groups of concentrated loads. This procedure would make use of the plasticity in tension mentioned earlier by $\mathrm{Mr}$ Rowe to suggest higher permissible apparent tensile stresses for the particular combination of stresses existing in end-blocks.

In composite construction, research into differential shrinkage and creep deflexion should enable the designer to define the long-term behaviour of his units more precisely. The tensile strain behaviour of the restrained in situ concrete could be used in stiffness calculations to produce more slender members.

The assessment of behaviour of sections would be considerably affected by improved knowledge of the failure criteria of concrete.

Turning to developments in analysis, $\mathrm{Mr}$ Rowe referred first to elastic design. It was difficult to envisage any new methods of elastic analysis since classical elastic theory was so well established, but the continued application of that theory to prestressed concrete with increased stresses was perfectly justifiable. With the help of computers to do the arithmetic, one could foresee the standardization of designs for bridges of up to $150 \mathrm{ft}$ span of specified widths, for types of bridge of greater span perhaps with triangulated girder construction, and for various types of shell roof with prestressed boundary members.
It seemed likely that design in the future would be increasingly on an ultimate load or an elastic-plastic basis. In the former category one could foresee the true limit analysis of an actual structure. At the same time, any composite action existing in the structure could be utilized in design.

Structures designed on an elastic-plastic basis would include those incorporating shear connectors of various types between adjacent beams, those using precast prestressed beams with in situ reinforced concrete, and those designed on the basis of a criterion other than a specific load factor.

Both these design procedures were relatively unexplored, yet they represented the rationalization of design philosophy and, as such, would dominate approaches to design in future.

$\mathrm{Mr}$ Rowe concluded by suggesting some types of structure that might be built with the help of the increased knowledge of the properties of prestressed concrete that he had anticipated.

To make the best use of land in the centres of cities, multi-storey structures for offices, shops and domestic purposes might span roads for vehicular traffic. This implied the design of foundation rafts for the structures as bridges of spans up to about $120 \mathrm{ft}$, having to sustain the load of perhaps 10 or 15 storeys above. These rafts could be designed either elastically or on an ultimate load basis using a load distribution procedure. It should be possible to prestress them in three dimensions, and so achieve slenderness by taking advantage of the three-dimensional state of stress. In the multi-storey structures themselves, use of the maximum spans would be a great advantage. These might well be achieved by taking advantage of higher permissible stresses in materials and by taking account of the stress distributions likely to exist in the members.

The roads themselves might be built as very wide bridges by using high-quality concrete members to form continuous longitudinal diaphragms resting on the foundation and spanning between them precast slabs stressed with an expansive cement. This would allow access to the complicated network of services needed in a city without disruption of road traffic.

The problems arising in the design and construction of urban elevated motorways could to a large extent be overcome by standardized designs and the use of precast units. There was considerable scope for the formulation of standard design approaches and construction procedures in which advantage could be taken of the combined states of stress that would exist in certain members.

With concrete of the higher strengths that might be expected and the use of prestressing, space frames with relatively slender members could readily be designed and constructed. With precasting, these should prove economical for a wide range of structures.

In this connexion, it was of interest to recall that Rüsch ${ }^{(1)}$ had stated that, in a triangulated beam for a 
bridge structure, prestressing could reduce secondary stresses to $25 \%$ of the primary stresses, whereas in a welded or rivetted steel truss, the figure was $100-150 \%$. Thus even now it was possible to construct concrete truss bridges of the same span/depth ratio as the equivalent steel structure. Exactly this had been done at Mangfall Bridge in Germany in 1958-60: prestressed concrete was used to replace a steel bridge of identical span/depth ratio.

It was clear that, given adequate facilities for research now, information could be obtained which, if accepted by the controlling authorities responsible for permissible design stresses, could lead to much more efficient use of prestressed concrete as a building material than was possible at present.

\section{REFERENCES}

1. RüsCH, H. Recent advances in the design and behaviour of concrete bridges. Proceedings of the American Society of Civil Engineers. Vol. 87, No. ST7. October 1961. pp. 199.

2. KLEIN, A. and Troxell, G. E. Studies of calcium sulfoaluminate admixtures for expansive cements. Reprint from the Proceedings of the American Society for Testing Materials. Vol. 58. 1958.

3. Klein, A., Karby, T. and POlivka, M. Properties of an expansive cement for chemical prestressing. Journal of the American Concrete Institute. Vol. 58, No. 1. July 1961. pp. 59.

\section{O R R I G E N D U M}

Magazine of Concrete Research No. 39.

pages 145 and 147 : Figures 6 and 12 (but not the captions)

should be transposed 